\title{
ЭТНОГРАФИЧЕСКИЕ ИССЛЕДОВАНИЯ НА КРАЙНЕМ СЕВЕРО-ВОСТОКЕ РОССИИ (историографический и методологический аспекты)
}

\author{
Л. Н. Хаховская \\ ФГБУН Северо-Восточный комплексный научно-исследовательский институт \\ им. Н. А. Шило ДВО РАН, г. Магадан \\ E-mail: hahovskaya@gmail.com
}

\begin{abstract}
Прослежена история этнографического изучения коренных народов, проживающих на Крайнем Северо-Востоке России с XVII в. по настоящее время. Освещены теоретические подходы в российской этнографии, прослежено их изменение в социально-политическом контексте. Проанализированы особенности содержания и стиля научных этнографических текстов в разные исторические эпохи. Показан широкий круг личностей и персоналий, связанных с этнографическим североведением, начиная от русских землепроходцев и заканчивая современными исследователями из центральных и региональных академических, образовательных и иных учреждений.
\end{abstract}

Ключевые слова: Крайний Северо-Восток России, коренные народы, этнография, методология, историография, полевые исследования, североведение.

DOI: 10.34078/1814-0998-2020-1-107-116

Введение. Цель статьи - описать историю региональных этнографических исследований, имея в виду исследования коренных народов, проживающих на Крайнем Северо-Востоке России. Основная наша задача - осветить изменение теоретических подходов, методологических рамок и, соответственно, содержания и стиля научных текстов и дискурсов. Речь также пойдет о политической и социальной обстановке, которая оказывала значительное влияние на научные исследования не только прямым путем, формируя взгляды ученых, но и косвенным, поскольку политические сдвиги преобразовывают ту социальную «материю», с которой приходится иметь дело этнографам.

Отметим, что термин «Крайний СевероВосток России» не соотносится со строго установленным географическим ареалом, но это понятие достаточно часто встречается в научной и публицистической литературе. Как правило, под ним подразумеваются Магаданская область, колымские районы Якутии, Чукотский автономный округ и северная часть Камчатки. Наше исследование также относится к этому региону, за исключением районов Якутии, так как историографически их целесообразнее рассматривать в административно-территориальных и

(C) Хаховская Л. Н., 2020 институциональных границах Республики Саха (Якутия). Поскольку в рамках журнальной статьи невозможно охватить все персоналии, связанные с этнографическим североведением, мы будем вести речь о людях, которые внесли наиболее значимый вклад в эту область гуманитарного знания.

Начальный период накопления этнографических знаний. В целом следует сказать, что этнографическая картина на российском СевероВостоке начинает проявляться в ходе открытия этих земель русскими землепроходцами, когда происходит накопление сведений о присоединяемых территориях и населяющих их народах. Историографическая периодизация определяет подобный рубеж как начало этнографического времени, периода «живых» свидетельств о народах, в отличие от предшествующего археологического времени, о котором повествуют лишь ископаемые источники. Именно такая познавательная ситуация обусловила гносеологическую особенность этнографии, в настоящее время подвергаемую постмодернистской критике как колониализм, колониальное сознание. Эта особенность заключается в том, что северные народы всегда изучаются «извне», внешним наблюдателем, который как бы их открывает и тем самым вызывает к исторической жизни. Постмодернистский эпистемологический сдвиг рассмотрен нами ниже. 
По отношению к народам Северо-Востока России этнографическое время началось с середины XVII в., времени первых письменных свидетельств. Историографы отмечают три основные парадигмальные особенности пространственного восприятия этого времени. Во-первых, феномен «господства текста над картой», что означает количественное преобладание и гораздо большую подробность вербальных описаний по сравнению с картографическими. Во-вторых, ярко выраженный антропоцентризм - в качестве основного репрезентанта присоединяемых территорий выступало обитавшее на них население. В-третьих, векторность русского фронтира с запада на восток, что обусловило восприятие нового через призму уже освоенного этнического пространства (Бурыкин, 2013).

Таким образом, первоначальные этнографические сведения отложились в результате амбивалентного стихийного эмпиризма русских: с одной стороны, они просто фиксировали наблюдаемые факты и состояния, с другой - интерпретировали наблюдаемое через знакомые зрительные и фонетические образы. Поэтому в казачьих «отписках» не только отражено имевшее место этническое и этнонимическое разнообразие $\mathrm{Ce}$ вера, но и прослеживается перенос этнических имен по аналогии на обширные или не связанные друг с другом группы. Например, наименование «тунгусы» распространялось на огромное число племенных и родовых группировок, расселенных на значительном удалении друг от друга и часто различавшихся по системе хозяйствования («оленные», «сидячие», «пешие»). В то же время некоторым группам, этнически близким «тунгусам», было присвоено наименование «ламуты» («ламутки», «ламские мужики»), при этом имелся в виду единственный признак проживания их вблизи крупных водоемов (оз. Байкал, Охотское море) (Сирина, 2012. С. 35-38, 40). В этот период казаки зачастую не различали коряков и чукчей, а под последними подразумевали эскимосов.

Опираясь на документы землепроходческой эпохи, можно говорить о большом многообразии этнических группировок на Севере; пестроте, текучести и неустойчивости их состава. Историографически северные народы в то время еще не очерчены сколько-нибудь определенно, их облик расплывчат, имена разнообразны, этнические признаки переменчивы. Эта неопределенность, однако, не совпадала с интересами государства, которое хотело иметь как можно более точные сведения об аборигенах Севера, руководствуясь общей амбициозной целью эффективного управления северными окраинами империи, а также более приземленной задачей фискального учета. Местные администрации начинают вести списки ясачных плательщиков, учитывая их в составе разнообразных родов и племен, что позволило внедрить налоговую систему в гущу «ино- родцев», но не давало и не могло дать общего представления о них. Лишь много позже, уже в советское время, известный этнограф-северовед Б. О. Долгих выявил и обобщил ясачные сведения, нарисовав на их основе масштабную картину обитавших на северных территориях народов в период второй половины XVII - первой половины XVIII в. (Долгих, 1960).

На эти же источники опирался крупный советский этнограф И. С. Гурвич, проследивший изменения в расселении и численности коренных северных народов за три столетия (с середины XVII в. до середины XX в.), а также изучивший этнические процессы в их среде (Гурвич, 1966). С методологической точки зрения, Долгих и в особенности Гурвич осуществили историческую реконструкцию, обладая знаниями о современной им этнографической обстановке, исходя из устоявшегося перечня народов и утвердившегося в науке представления об их этническом облике и происхождении. Иначе говоря, это был эпистемологический процесс, обратный актуализации прошлого, который условно можно обозначить как ревитализацию рецентности.

Комплексные экспедиции XVIII в. Потребность российской власти знать «в лицо» населяющих империю подданных аборигенного происхождения привела к появлению своего рода государственного заказа на изучение коренных народов Севера. В XVIII в. организуются северные экспедиции, включавшие специальные программы для сбора этнографического материала; появляются первые крупные этнографические работы, впоследствии ставшие выдающимися памятниками исторической мысли. Основы комплексного изучения этносов заложили участники Второй Камчатской экспедиции С. П. Крашенинников (1949) и Г. В. Стеллер (1999), оставившие капитальные труды с описанием коренных жителей Камчатки - коряков, ительменов, айнов. К этим трудам тесно примыкают работы Я. И. Линденау (1983), хотя и не столь фундаментальные, но крайне значимые с содержательной точки зрения. В частности, Линденау единственный в историографии описал оседлых коряков, живших на Охотском побережье у устьев рр. Сиглан и Яма.

Эти исследователи руководствовались программой Г. Ф. Миллера, включавшей перечень вопросов, ответы на которые должны были исчерпывающим образом характеризовать каждый отдельный этнос. Этнографические тексты поэтому разделены на соответствующие рубрики - происхождение, название, занятия, религия, одежда, жилища и т. д. Вследствие этого достигалось определенное структурное единообразие и задавался канон академического труда по этнографии, существующий до настоящего времени, хотя и в несколько измененном виде.

Неразрывная связанность геополитических и научных этнографических задач нашла яркое выра- 
жение в Северо-Восточной географической экспедиции 1785-1795 гг. Важная цель экспедиции, направленной на усиление влияния России на Тихоокеанском побережье, заключалась в необходимости «сколько возможно сведать о земле чукчей, силе и нравах сего народа» (Этнографические..., 1978. С. 5). Усилия К. Мерка, Г. А. Сарычева, И. Биллингca, И. Кобелева, Н. Дауркина и других участников, собравших ценные этнографические материалы, способствовали нормализации межэтнических отношений. Не случайно именно в это время чукчи, хотя и в значительной степени формально, были приведены в российское подданство.

В этот период впервые проявилось идейное влияние западной общественной мысли на развитие российской этнографии, хотя оформление ее как самостоятельной научной дисциплины произошло много позже. Этнографическое многообразие северных территорий преломлялось сквозь призму национализма - идеологии, характерной для Нового времени, главными носителями которой были Англия, Нидерланды, Франция и, позднее, Германия (Соколовский, 2008). Основополагающее онтологическое и аксиологическое значение в идеологии национализма придается нации, под которой подразумевается автономное и самодостаточное сообщество людей (как правило, это гомогенный народ) с объективными культурно-этническими признаками. Национализм подчеркивает индивидуальность и колорит наций и сопряженных с ними народов, а потому задачей науки становится изучение социальной среды в разрезе этнических группировок и выявление характерных черт их культуры.

С этого времени этноориентированная диагностика культурных явлений становится доминирующим способом познания при соприкосновении наблюдателей с населением Севера, что отразилось в способе вербализации и интерпретации полученных знаний как на научном, так и на повседневном уровне. Наиболее важно, однако, то, что национализм стал государственной идеей, и через сеть видимых и невидимых институций государство транслировало эту идею в научную среду и в широкие массы. Стремление государственных органов постпетровского времени учитывать народы на основе четко выраженных критериев, то есть классифицировать и каталогизировать их, определять численность, выявлять характерные занятия, обычаи, внешний облик, «привязывать» к территориям проживания останется таковым вплоть до настоящего времени.

Этнографические исследования в XIX - начале XX в. B XIX в. приоритет в этнографическом изучении автохтонов Северо-Востока, инициируемом правительством, продолжает сохраняться за северными территориями Тихоокеанского побережья, что соответствует важнейшему вектору геополитических интересов того времени. Поэтому в результате ряда мореплаваний (Ф. П. Врангеля,
О. Е. Коцебу, А. Е. Норденшельда и др.), специальных сухопутных и морских экспедиций гражданских и военных чинов (Г. Майдель, А. А. Ресин, А. В. Олсуфьев и др.) в историографии отложились сведения преимущественно о чукчах и эскимосах, основных обитателях этого ареала.

Обозначились и новые тенденции. Во-первых, значительный вклад в исследование коренных жителей Чукотки внесли чиновники, непосредственно занятые государственным управлением на местах, - начальники образованной в 1888 г. Анадырской округи Л. Ф. Гриневецкий, Н. Л. Гондатти и Н. П. Сокольников. Видя в этой деятельности свой общественный долг, они устанавливали связь с появлявшимися в то время научными учреждениями краеведческого направления. В их научное наследие, помимо письменных источников и фотографий, входят имеющие непреходящую научную ценность этнографические коллекции. Во-вторых, важными поставщиками этнографических сведений становятся люди, не имевшие прямого отношения ни к зарождавшейся этнографической науке, ни к военной или чиновничьей службе, но оказавшиеся в соприкосновении с народами Северо-Востока вследствие выполнения своих основных обязанностей. Это священники, миссионеры, путешественники, специалисты разных профессий (И. Е. Вениаминов, А. И. Аргентов, А. А. Богородский, Н. В. Слюнин, К. Дитмар, К. И. Богданович и др.). Как правило, они были внимательными и заинтересованными наблюдателями, и им мы обязаны замечательными описаниями местных культур.

Например, охотский окружной врач А. А. Богородский зафиксировал распространение среди тайгоносских коряков массовых слухов о скором пришествии сверхъестественного существа Кюйкеняха, который наделит всех «огромными табунами златорогих оленей» (Богородский, 1853. С. 85). В ожидании божественного дара коряки будто бы проели всех своих оленей, чем и объясняли собственную бедность. Автор не дает объяснение этому случаю, но можно предположить, что импульсом к нему стало внедрение христианской религии, которая наложилась на традиционные верования в ворона-первопредка.

Исследователи XIX в., как правило, были люди просвещенные, образованные, многие из них имели подготовку в области естественных наук. Поэтому их восприятие этнографической реальности базировалось на естественнонаучных методологических установках. Теоретической основой этнографических исследований становятся господствовавшие в науке в то время позитивизм и эволюционизм. Позитивистский подход полагает единственным истинным источником знания конкретные эмпирические исследования и требует фиксировать факты объективно, «как они есть». Эволюционистская концепция в общем виде провозглашает исторически прогрессивное движение 
всего материального мира от низших форм к высшим, а в применении к наукам о социуме подразумевает постепенный переход всех человеческих групп от простого общественного устройства к более развитому и сложному.

Этот концептуальный фундамент имел важные эпистемологические последствия для этнографической науки. Во-первых, имплицитно сформировалось представление о народах как естественных образованиях, своего рода социальных организмах, неразрывно связанных с определенной территорией, наделенных объективными признаками, которые в предельном выражении остаются неизменными. Это представление хорошо согласовывалось с националистической идеей о том, что каждый народ имеет право на собственную землю и собственную государственность. Во-вторых, народы выступали в качестве объекта наблюдения и управления, поскольку, в-третьих, исследователи делали упор на необходимость прогрессивных социальных изменений у северных автохтонов, избавления их от «отсталости», «дикости», приобщения к европейской/ российской цивилизации как в духовном, так и в материальном плане. Следует отметить, что эти установки в отечественной науке и государственном управлении получили чрезвычайное развитие в советское время и доминируют до сих пор.

Классический период этнографии СевероВостока России связан с именами В. И. Иохельсона и В. Г. Богораза, которые осуществили исследование аборигенной культуры, хотя и подвергшейся трансформации, но все же в значительной мере сохранявшей традиционный облик. Вершиной исследовательского успеха этих двух ученых стали результаты, полученные в ходе Джезуповской экспедиции, которая на российской территории прошла в 1900-1902 гг. (Gateways, 2001; Constructing..., 2003; Вахтин, 2005). Идейным вдохновителем Джезупа был американский исследователь Франц Боас, стоявший на теоретической платформе эмпиризма и культурного релятивизма. Боас считал самоценной, внутренне связанной и цельной культуру каждого аборигенного народа и требовал начинать этнографию (в американской научной традиции - культурную антропологию) с «чистого листа», путем составления максимально полного реестра культурных черт того или иного народа. Кроме того, основополагающее значение Боас придавал сравнительному методу, поиску связей и сходств между народами и культурами. Именно с этой целью Боас инициировал исследование автохтонных народов российского Северо-Востока.

Иохельсон и Богораз представляют собой характерный только для российской действительности тип «этнографа поневоле», так как, будучи сосланными на Северо-Восток из-за своей революционной деятельности (они были членами группы «Народная воля»), живя здесь бок о бок с местными жителями, они восприняли «социальное задание эпохи» (Богораз, 1934: XIII) описать их жизнь и культуру, до той поры почти неизвестную широкой аудитории. Результатом экспедиции стала огромная коллекция вещей и фотографий, ныне хранящихся в США, а также целый ряд монографий (Богораз, 1934, 1939; Jochelson, 1905 и др.), развивших тот канон академического труда, который был заложен Крашенинниковым и Стеллером. Богораз и Иохельсон не имели какого-либо законченного образования, но получили от Боаса инструкции методологического и организационного плана, которые и применили на практике. Они настолько тщательно и убедительно зафиксировали все стороны жизни изучаемых народов, что их труды до сих пор остаются энциклопедией по культуре чукчей, коряков и юкагиров. Богораз, кроме того, становится самой авторитетной фигурой в российской/советской этнографии первой трети XX в.

Становление этнографии в советское время. В 1920-1930-х гг. начался пионерный для советского времени этап этнографических исследований, в котором научные цели тесно переплетались с прикладными задачами. Это была двуединая и потому амбивалентная государственная политика - с одной стороны, изучить и сохранить самобытность и культуру северных автохтонов, с другой - продвинуть их на пути прогресса. Идея культуры, составляющей неотъемлемый элемент этноса, принимает политизированный характер, поскольку для ее сохранения задействуются рычаги и институты государственного строительства и управления. Большую роль сыграл Комитет Севера при ВЦИК, усилиями которого была проведена Приполярная перепись 1926/27 г., послужившая основой для землеустройства и коллективизации на Севере. Этносохраняющее устремление советского государства на северных окраинах обрело форму этнокультурной автономии, при которой каждый «крупный» северный народ получил «собственную» территориально-административную единицу - округ, область или район.

Этнографы первоначального советского времени в значительной мере унаследовали идейный и научный багаж предшествующего периода, так как у истоков советской этнографии стояли бывшие ссыльные народовольцы, впоследствии профессора советской высшей школы В. Г. Богораз и Л. Я. Штернберг. В это время, однако, все большее значение придается эволюционистской теории в ее заостренной, обусловленной марксистским учением форме. Если раньше Богораз мог декларировать приверженность сопряженной с релятивизмом диффузионистской теории, то теперь он был вынужден заявлять о своей «перестройке» на марксистские идейные и идеологические «рельсы» (От классиков..., 2014). Более того, эволюционизм первых советских этнографов из теорети- 
ческой плоскости переходил в практическую, так как предполагалось, что они будут способствовать продвижению коренных северных народов от их «отсталого» состояния к более прогрессивному общественному устройству.

Действительно, основная масса этнографов, работавших в то время на Северо-Востоке, совмещала научные исследования с конкретной работой в советских учреждениях - школах, культбазах, кооперативах, местных органах власти. В местах проживания эвенов, чукчей, юкагиров, коряков плодотворно работали К. И. Бауэрман, Н. Н. Билибин, И. С. Вдовин, В. И. Левин, М. Г. Левин, Г. А. Меновщиков, К. А. Новикова, Е. П. Орлова, С. Н. Стебницкий, А. С. Форштейн и многие другие. Также весьма важные особенности культуры народов Северо-Востока описали ученыеестественники (Б. В. Зонов, С. В. Обручев и др.).

Например, геолог С. В. Обручев при перекочевке в 1935 г. по Чаунской тундре зафиксировал устойчивость палеоазиатского способа запряжки оленей, которая не позволяла увеличить количество впрягаемых животных и, соответственно, объем перевозимого груза. Он попытался побудить чукчей к использованию более рациональной якутской запряжки, но встретил стойкое сопротивление, которое убедительно объяснил запретом религиозного характера (Обручев, 1974. С. 69, 70).

Первые советские десятилетия ознаменовались выходом в свет большого количеств публикаций, как правило, в формате журнальных статей, по стилю напоминающих оперативные репортажи с места разворачивания активных советских преобразований. Авторы заинтересованно подмечали многие местные черты культуры и поведения, фиксировали происходящие и декларировали желаемые изменения, говорили о конкретных людях и событиях, часто подчеркивали собственную роль в этнических процессах и этностроительстве. Эти материалы отмечены динамикой, процессуальностью, актуализацией текущего момента. В научной сфере существовали достаточно разнообразные взгляды, шла активная полемика, в том числе по теоретическим вопросам.

Вместе с тем именно в 1920-1930-е гг. были заложены основы государственной практики персонального и коллективного приписывания к официально признаваемым категориям этнической принадлежности. Другими словами, шло формирование жестких рамок, в которые укладывалось все этническое разнообразие Севера. Появился перечень коренных малочисленных народов Севера из 26 наименований, регулировавший предоставление индивидуальных и групповых льгот. Эти и другие инструменты государственной политики имели важные этнообразующие последствия, поскольку влияли на этническое самосознание и самоотнесение.

В этот период также происходит институциональное «укоренение» этнографии как науч- ной дисциплины, исследовательский процесс из практической сферы постепенно переносится в академическую. В 1933 г. в Ленинграде создается Институт антропологии и этнографии Академии наук СССР (впоследствии менявший название и месторасположение), который все последующие советские десятилетия определял стратегию развития этнографии в теоретическом и организационном плане. В частности, изменился принцип организации полевых исследований. Богораз и Штернберг, помимо идейного багажа, транслировали в профессиональную сферу собственный полевой опыт (Арзютов, Кан, 2013). Они требовали длительного, в течение нескольких непрерывных лет, нахождения в среде изучаемого народа, что и осуществили этнографы-активисты первых советских десятилетий. На «академическом» этапе полевые экспедиции становятся сезонными, менее продолжительными, но более регулярными и специализированными.

Единственным полевым исследованием последующих советских лет, проведенным в строгом соответствии с установками Богораза Штернберга, стало трехлетнее (1948-1951 гг.) кочевание ленинградского этнографа В. Г. Кузнецовой с амгуэмскими чукчами (Хаховская, 2016). Результатом ее работы являются уникальные фотоматериалы, обширный полевой дневник и единственная научная статья (Кузнецова, 1957). Научное наследие Кузнецовой в определенной степени отражает тенденцию развития советской этнографии во второй половине XX в. Контраст между содержанием ее дневника и статьи демонстрирует концептуальный и стилистический нарративный сдвиг, произошедший вследствие перехода этнографов от советского активизма к академической респектабельности. Дневник написан от первого лица, он повествует о ежедневных событиях отдельного чукотского стойбища, конкретных людях, их высказываниях, отношениях между собой; в жизнь стойбища вплетены действия, мысли и иногда эмоции самого автора. Статья же написана в беспристрастной, отстраненной и обобщающей манере (что ни в коей мере не умаляет ее непреходящей научной ценности), как если бы автор видел происходящее с большой дистанции.

Развитие советской этнографии во второй половине XX в. В послевоенный советский период активное изучение Севера продолжается. В 1945 г. Институт этнографии совместно с Институтом истории материальной культуры организует Северо-Восточную комплексную экспедицию, нацеленную прежде всего на изучение древней истории. В 1955 г. в Московском отделении Института создается Сектор по изучению социалистического строительства у малых народностей Севера, а год спустя начинает действовать Северная экспедиция, охватившая полевыми исследованиями многие местности Крайнего Се- 
вера (Батьянова, 2013). Официальная концепция развития этнографии состояла в ориентации на современность, вместе с тем сохраняет актуальность изучение ранних этапов этнической истории и первобытно-общинной формации.

Познавательная ситуация, сложившаяся в советском этнографическом североведении, имела ряд особенностей, которые наложили отпечаток на формирование взглядов ученых, на содержание и стиль презентации полученных результатов. Во-первых, они испытывали сильное влияние установок, методов и методологии, характерных для археологической дисциплины. С этим связано большое внимание к этногенезу, поиску первоначальных истоков и прародины изучаемых народов. Во-вторых, в полевой и «кабинетной» практике достаточно последовательно осуществлялся принцип «один исследователь - один народ», так что историография практически каждого коренного народа ассоциируется с именем одного-двух ведущих ученых. Обе эти предпосылки повлекли важные гносеологические последствия. Поскольку этнографы стремились выделить наиболее яркие отличительные признаки на максимально возможной хронологической глубине, выскристаллизовывался некий обобщенный этнический облик каждого таким образом изучаемого народа. Однажды зафиксированные традиционные этнокультурные признаки распространялись на группу в целом в размытом временном диапазоне, оставляя мало места для локальных и микролокальных особенностей и различий.

Далее, происходит дальнейшая объективизация научной позиции. В позитивистски ориентированной советской этнографической науке предполагалось, что специально обученные наблюдатели транслируют наблюдаемое непосредственно, т. е. открывают читателю прямое, ничем не искаженное видение событий и состояний. В этом случае личность наблюдателя выключена из процесса изучения, и этнограф в поле представляет собой образец беспристрастного фиксатора культуры, описывающего ее как естественнонаучный испытатель. Соответственно, в академических трудах автор всегда вынесен «за скобки», он ведет повествование из нейтральной позиции, не осложненной личной рефлексией. В 1960-1970-х гг. директор головного института Ю. В. Бромлей разработал официальную дисциплинарную концепцию - советскую теорию этноса, которая обосновывала механизмы и этапы исторического развития этносов, типологию и иерархию этнических общностей, их сущность и признаки. В результате этническая интерпретация культурной отличительности становится самодовлеющим методом научной репрезентации. Наиболее характерная форма публикаций этого периода - монографии и коллективные тематические сборники, в которых материал излагался в разрезе этносов.
С крупными обобщающими исследованиями выступили североведы С. А. Арутюнов, В. В. Антропова, И. С. Вдовин, В. В. Горбачева, И. С. Гурвич, М. Я. Жорницкая, И. И. Крупник, Г. А. Меновщиков, Ю. Б. Симченко и др. Их усилиями была создана школа советского североведения, сочетавшая научные и прикладные задачи, а в число последних, помимо активизации процесса социалистических преобразований на Севере, входила защита «национальных прав северных народов» (Батьянова, 2013. С. 28).

На фоне академических этнографических изданий по народам Крайнего Северо-Востока выделяется книга В. В. Лебедева и Ю. Б. Симченко «Ачайваямская весна» (1983), повествующая об их полевой работе среди коренных жителях Камчатки и Чукотки. Она характеризуется особым подходом и стилем авторов, которые сами активно присутствуют на страницах, представляют своих героев, озвучивают действия, размышления, отношение к наблюдаемой реальности. По сути, такие работы стали предвестниками распространившейся в постсоветское время постмодернистской методологической платформы, которая требовала обозначать позицию наблюдателя, вскрывать субъективную подоплеку исследований и давать право голоса тем, кого этнографы изучают.

Региональные этнографические исследования советского периода. В результате расширения сети академических учреждений важную роль в этнографических исследованиях СевероВостока России начинают играть региональные специалисты. Северо-Восточный комплексный научно-исследовательский институт (СВКНИИ) Сибирского отделения АН СССР с самого момента организации в 1960 г. имел в своем составе отдел (впоследствии лабораторию), призванный изучать историю и культуру коренных народов. Возглавил отдел выдающийся археолог Н. Н. Диков, чьи исследования составили целую эпоху в региональной исторической дисциплине. Это была яркая эпоха, отмеченная археологическими открытиями мирового уровня, разработкой глобальных исторических концепций, обширными теоретическими обобщениями.

В научно-исследовательской программе Н. Н. Дикова важное значение имел этнографический подход, предполагавший изучение исторических явлений в этническом разрезе. Реализация данного подхода повлекла за собой сильную вовлеченность историков СВКНИИ (прежде всего археологов) в этногенетические и этноисторические исследования. Археологические стоянки, открываемые на Крайнем Северо-Востоке, рассматривались в этнических координатах, такого рода «привязка» стала обязательным элементом исторического прочтения археологических древностей (Хаховская, 2017). Эта программа также давала возможность координировать все отрасли исторического знания через единство объекта ис- 
следования - аборигенные народы Магаданской и Камчатской областей. В итоге многолетних полевых работ Н. Н. Дикова, Т. М. Диковой, Т. С. Теина, А. И. Лебединцева, М. А. Кирьяк-Диковой, С. Б. Слободина, а также археологов краеведческих музеев И. Е. Воробья, А. К. Пономаренко, А. В. Пташинского отдаленное прошлое края обрело зримые очертания и было соотнесено с развитием современных коренных народов.

Собственно этнографические региональные исследования этого периода связаны прежде всего с именами известных ученых У. Г. Поповой и В. В. Леонтьева. Следует, однако, отметить, что первые шаги в этом направлении сделала сотрудник (впоследствии директор) Магаданского краеведческого музея А. В. Беляева - начиная с 1954 г. она провела ряд этнографических полевых экспедиций, выпустила несколько работ. В этом музее начинала этнографические исследования и У. Г. Попова.

Придя в СВКНИИ в 1960 г., Попова приступила к изучению оседлого этнически смешанного населения Охотского побережья, а с 1965 г. вплотную занялась эвенской этнографией, до той поры освещенной крайне слабо. Региональная этнография, в соответствии с общей установкой, была нацелена на изучение социалистической реконструкции хозяйства и быта аборигенов, современного состояния их культуры. Именно эта задача стояла перед У. Г. Поповой. B. В. Леонтьев, поступивший в СВКНИИ в 1964 г., также начал разработку темы «Народы Чукотки на современном этапе коммунистического строительства (1958-1967 гг.)», которая увенчалась защитой кандидатской диссертации и публикацией монографии (Леонтьев, 1973). Между тем установка на рецентность шла вразрез с методологией, подразумевавшей обобщение, выявление общих культурных черт и прослеживание их истоков. Задача фиксировать этничность как состояние «здесь и сейчас» в те годы не могла быть исчерпана современным синхронным срезом, а неизбежно отсылала в прошлое. Именно поэтому этнографы, призванные освещать достижения социалистического этапа развития коренных народов, не могли ограничиться этим периодом, а «достраивали» свои исследования, обращаясь к более ранней истории.

Действительно, оба исследователя вышли из предписанных хронологических рамок, поскольку фактический материал и внутренняя логика дисциплины «толкали» их назад, в прошлое. Этот весьма симптоматичный сдвиг в научных интересах обоих этнографов привел Попову к рассохинским эвенам, а Леонтьева - к керекам. Изучая социалистическую современность, Попова, судя по всему, столкнулась с неудовлетворительным состоянием собственно этнографических источников, нехваткой конкретного материала. В поисках этого материала она едет к рассохинским эве- нам, которые в то время являлись своего рода этнографическим реликтом. На Рассохе еще можно было воочию увидеть те традиции, которая уже исчезли из жизни остальных эвенов, захваченных советским бытом и культурой. Именно на этнографическом материале рассохинцев Попова впоследствии решала такие внутридисциплинарные задачи, как реконструкция архаичной социальной организации эвенов, выделение типов традиционных хозяйств, исследование религиозных представлений, ритуалов и шаманских практик (Попова, 1976, 1981).

В. В. Леонтьев от эволюционно-социалистической проблематики перешел к чисто этнографической теме, нейтральной по отношению к политическому строю и идеологии - культуре и фольклору кереков. На этом этапе своего научного творчества Леонтьев состоялся как «чистый» этнограф, проследивший генетические корни и культурный облик данной этнической группы (Леонтьев, 1983). Он совершил три экспедиционные поездки к керекам (1972, 1973, 1975 г.), причем в последней из них совместно с археологом А. А. Ореховым провел также исследование береговой черты от Анадырского лимана до пос. Хатырка. Уникальным достижением Леонтьева стал фундаментальный «Топонимический словарь Северо-Востока СССР» (в соавторстве с К. А. Новиковой), в работе над которым ему помогала Р. М. Рагтытваль, известная также по статье о священных предметах мейныпыльгинских чукчей.

Значительный вклад в этнографию эскимосов внес археолог Т. С. Теин, опиравшийся на впечатления своего детства и юности $(1975,1992)$. Кроме того, он имел опыт участия в качестве эксперта в возрождаемых в позднесоветский период эскимосских традиционных праздниках.

Современное состояние этнографического североведения. В постсоветский период в этнографической дисциплине произошел методологический «обвал». Советская теория этноса как руководящая доктрина рухнула в одночасье, на освободившемся пространстве получили развитие теоретические подходы, лежащие в русле постмодернистской парадигмы, что явилось следствием западного интеллектуального влияния. Прежде единый объект этнографических исследований - какое-либо целостное этническое образование - оказался разбит на отдельные фрагменты, которые, кроме того, теряли этническое «лицо». Культурные различия и особенности теперь совсем не обязательно рассматривались сквозь призму этнической принадлежности их носителей. Они могли характеризовать какую угодно социальную группу. Более того, прежнее позиционирование подобных групп в качестве объектов научного изучения подверглось критике. Критические голоса звучали не только среди ученых, но и более широкой аудитории. Например, известный чукотский 
писатель Ю. Рытхэу выступал против особенно активного в перестроечные годы «открытия» Чукотки многочисленными научными экспедициями и путешественниками-экстремалами. Он считал, что это принижает роль местного населения, которое живет и трудится здесь без всякой героизации. Получение моральных и иных дивидендов за счет пусть и непреднамеренного приписывания местным жителям роли объекта, а не субъекта истории он назвал «географическим империализмом» (Рытхэу, 1991).

Состояние субъекта исследования также не осталось неизменным. Постмодернистская критика дезавуировала позитивистские претензии на беспристрастный и объективный характер гуманитарного знания, ввела в поле анализа самого наблюдателя, свойственные ему мировоззренческие установки, ценностные ориентиры, эмоциональный настрой, даже житейские привычки и пристрастия.

Постмодернистский подход, в противовес позитивистскому примордиализму (к которому была причислена советская теория этноса), показывает, что общественные группы, в том числе этносы, образуются не сами по себе, естественным путем, а во многом являются результатом внешнего исторического процесса, предписаний и социальных практик со стороны государства, органов власти, политиков, ученых и других институций и акторов. И сами носители этнических различий («этнофоры», в терминах советской теории этноса), отнюдь не пассивны и не безразличны к этим внешним вызовам, а реализуют свой собственный выбор. Следствием методологической «перестройки» стали отсутствие обобщающей, «большой» теории и расцвет множества концепций, применяемых ad hoc, к отдельно взятому случаю или, как сейчас принято говорить, кейсу.

Нынешнее положение этнографии (в настоящее время ее также именуют этнологией, социокультурной антропологией) в определенной степени напоминает ситуацию 1920-1930-х гг. - существует теоретический плюрализм, дискуссии, произошел расцвет журнальных публикаций в противовес монографической форме изложения.

Общеразделяемым подходом в дисциплине стало положение, согласно которому традиционная культура и этничность жестко не связаны между собой, поскольку в границах этнической группы существует вариативность культурных форм (необязательно традиционных), и, напротив, один и тот же культурный комплекс могут разделять несколько этнических и иных формирований (или их подразделений). В современном мире векторы развития этничности и традиционной культуры, как правило, направлены противоположно: угасание традиции влечет за собой не утрату, а активизацию этничности, в первую очередь этнического самосознания. Одновременно с этим этническое самосознание часто является неоднозначным, многоуровневым и актуализируется ситуационно.

Современные этнографические исследования на Крайнем Северо-Востоке России активно проводят региональные этнографы, дислоцированные в Магадане (С. В. Будникова, В. В. Доржеева, Л. Н. Хаховская и др.); Анадыре (Н. И. Вуквукай, В. В. Голбцева, В. Н. Нувано, О. П. Коломиец, Е. А. Церковникова, А. А. Ярзуткина и др.); Владивостоке (В. А. Тураев). На основании полевых, архивных и музейных источников описываются и анализируются сюжеты из традиционной и современной жизни коренных народов региона, прослеживается их развитие на крупных хронологических отрезках. На Чукотке особое внимание придают изучению тенденций современной городской и сельской жизни аборигенного населения, последствиям промышленного освоения территории (Коломиец, 2018). Большое значение имеют междисциплинарные исследования в сфере традиционных и современных религий (А. И. Поспелова), этнопедагогики (А. Н. Фролова) и др.

Исследования антропологов из центральных российских академических и образовательных учреждений (Е. П. Батьянова, А. А. Бурыкин, А. В. Головнев, В. Н. Давыдов, Е. А. Давыдова, Д. А. Опарин, А. А. Сирина и др.) играют большую роль в развитии российского североведения, совершенствовании методологических концепций и методов полевой работы. Стоит отметить, что в связи с политическими и экономическими реформами последних десятилетий повысилась исследовательская конкуренция в регионе. В этнографическом «поле» российских ученых существенно «потеснили» лингвисты, социальные и культурные антропологи из США, Японии, Франции и других стран (В. Ватте, П. Грей, А. Кинг, М. Куребито, Я. Панакова и др.). Благодаря международному научному сотрудничеству и обмену интеллектуальными достижениями региональные этнографические исследования получают новый импульс.

\section{ЛИТЕРАТУРА}

Арзютов Д. В., Кан С. А. Концепция поля и полевой работы в ранней советской этнографии // Этнографическое обозрение. 2013. № 6. С. 45-68.

Батьянова Е. П. Северная экспедиция Института этнографии (1956-1991 гг.) // Там же. 2013. № 4. C. $17-34$

Богораз В. Г. Чукчи.

Ч. 1. Л. : Изд-во Ин-та Народов Севера, 1934. 192 с.

Ч. 2. Л. : Изд-во Главсевморпути, 1939. 211 с.

Богородский А. А. Медико-топографическое описание Гижигинского округа // Журнал Министерства внутренних дел. 1853. Ч. 2. Отд. 3. С. 49-138.

Бурыкин А. А. Имена собственные как исторический источник: По материалам русских документов об открытии и освоении Сибири и Дальнего Востока 
России XVII-XIX веков. СПб. : Петербургское Востоковедение, 2013. 536 с.

Вахтин Н. Б. Тихоокеанская экспедиция Джесупа и ее русские участники // Антропологический форум. 2005. № 2. С. 241-274.

Гурвич И. С. Этническая история Северо-Востока Сибири. М. : Наука, 1966. 276 с.

Долгих Б. О. Родовой и племенной состав народов Сибири в XVII в. М. : Изд-во АН СССР, 1960. 622 с.

Коломиеи О. П. Из истории развития этнографии на Чукотке // Этнография. 2018. № 2. С. 188-196.

Крашенинников С. П. Описание земли Камчатки. М.; Л. : Изд-во Главсевморпути, 1949. 847 с.

Кузнецова В. Г. Материалы по праздникам и обрядам амгуэмских оленных чукчей // Сибирский этнограф сборник. Вып. 2. (Тр. Ин-та этнографии. Нов. сер. Т. 35). М.; Л., 1957. С. 263-326.

Лебедев В. В., Симченко Ю. Б. Ачайваямская весна. М. : Мысль, 1983. 143 с.

Леонтьев В. В. Хозяйство и культура народов Чукотки (1958-1970 гг.). Новосибирск : Наука, 1973. $178 \mathrm{c}$.

Леонтьев В. В. Этнография и фольклор кереков. М. : Наука, 1983. 136 с.

Линденау Я. И. Описание народов Сибири (первая половина XVIII века). Магадан : Кн. изд-во, 1983. 176 с.

Обручев C. B. По горам и тундрам Чукотки. Магадан : Кн. изд-во, 1974. 208 с.

Oт классиков к марксизму / совещание этнографов Москвы и Ленинграда (5-11 апр. 1929 г.). СПб. : МАЭ РАН, 2014. 511 c.

Попова У. Г. Рассохинская группа эвенов // Экономические и исторические исследования на СевероВостоке СССР. Магадан, 1976. С.121-140.

Попова У. Г. Эвены Магаданской области: очерки истории, хозяйства и культуры эвенов Охотского побережья 1917-1977 гг. М. : Наука, 1981. 304 с.
Pblтхэу Ю. Терпеливое гостеприимство // Советская Чукотка. 16.04.1991.

Сирина А. А. Эвенки и эвены в современном мире: самосознание, природопользование, мировоззрение. М. : Вост. Лит., 2012. 604 с.

Соколовский С. В. Институты и практики производства и воспроизводства этничности // Демоскоп. № 319-320 (4-17 февр. 2008) [Электрон. ресурс]. URL: http://www.demoscope.ru/weekly/2008/0319/analit02.php

Стеллер Г. В. Описание земли Камчатки. П.-Камчатский : Камчат. печатный двор, 1999. 287 с.

Теин Т. С. Эскимосский праздник кита «полъа» (на примере поселка Наукан) // Краеведческие записки. Магадан : Кн. изд-во, 1975. Вып. 10. С. 88-94.

Теин Т. С. И было так. Очерки традиционной культуры азиатских эскимосов. Магадан : Обл. центр народного творчества и досуга, 1992. 65 с.

Хаховская Л. Н. Полевые исследования Варвары Григорьевны Кузнецовой в амгуэмской тундре // Этнографическое обозрение. 2016. № 3. С. 83-95.

Хаховская Л. Н. Этнографические проблемы в научно-исследовательской программе Н. Н. Дикова // Проблемы истории, филологии и культуры. 2017. № 1. С. 304-318.

Этнографические материалы Северо-Восточной географической экспедиции: 1785-1795 гг. Магадан : Кн. изд-во, 1978. 176 с.

Constructing Cultures Then and Now / eds. L. Kendall, I. Krupnik. Washingnton DC, 2003. 364 p.

Gateways. Exploring the Legacy of the Jesup North Pacific Expedititon, 1897-1902 / eds. I. Krupnik, W. W. Fitzhugh. Washingnton DC, 2001. 335 p.

Jochelson $W$. The Koryak // The Jesup North Pacific Expedition Publications. Vol. VI. Part. I-II. Memoirs of the American Museum of Natural History. New York, Leiden : E. J. Brill; New York : G. E. Stechert \& Co., 1905. 842 p.

Поступила в редакичю 23.12.2019 2.

Поступила после доработки 09.01.2020 2.

\title{
ETHNOGRAPHIC RESEARCH IN THE FAR NORTH-EAST OF RUSSIA (Historiographical and Methodological Aspects)
}

\section{N. Khakhovskaya}

\author{
North-East Interdisciplinary Scientific Research Institute n. a. N. A. Shilo, FEB RAS, Magadan
}

The author traced the history of ethnographic study of indigenous peoples living in the Far NorthEast of Russia from the $17^{\text {th }}$ century until the present day. The theoretical approaches in Russian ethnography are highlighted. A change in the methodology of scientific research in the socio-political context is revealed. The features of the content and style of scientific ethnographic texts in different historical eras are analyzed. The article presents a wide range of personalities involved with ethnographic Arctic and Northern studies, from Russian pioneers of the North to current researchers from central and regional research, educational, and other institutions.

Keywords: Far North-East of Russia, indigenous peoples, ethnography, methodology, historiography, field research, Arctic and Northern studies. 


\section{REFERENCES}

Arziutov, D. V.; Kan, S. A., 2013, The Concept of Field and Field Work in Early Soviet Ethnography, Etnograficheskoe Obozrenie, 6, 45-68 [In Russian].

Batyanova, E. P., 2013, Northern Expedition of the Institute of Ethnography (1956-1991), Ibid., 4, 17-34 [In Russian].

Bogoraz, V. G., 1934, The Chukchi, Part I, Leningrad, Institute of the Peoples of the North [In Russian].

Bogoraz, V. G., 1939, The Chukchi, Part II, Leningrad, Glavsevmorput' [In Russian].

Bogorodsky, A. A., 1853, Medical and Topographical Description of the Gizhiga District, Zhurnal Ministerstva Vnutrennikh Del, Part II, Division III, 49-138 [In Russian].

Burykin, A. A., 2013, Proper Names as a Historical Source: By Materials from Russian Documents on the Discovery and Exploration of Siberia and of the Far East of Russia in the $17^{\text {th }}-19^{\text {th }}$ Centuries, St. Petersburg, Peterburgskoye Vostokovedeniye [In Russian].

Constructing Cultures Then and Now, 2003, Eds. L. Kendall, I. Krupnik, Washingnton DC.

Dolgikh, B. O., 1960, Clan and Tribal Composition of the Peoples of Siberia in the $17^{\text {th }}$ Century, Moscow, AS USSR [In Russian].

Ethnographic Materials of the Northeast Geographical Expedition (1785-1795), 1978, Magadan [In Russian].

From the Classics to Marxism : Meeting of Moscow and Leningrad Ethnographers (April 5-11, 1929), 2014, St. Petersburg, MAE RAS [In Russian].

Gateways. Exploring the Legacy of the Jesup North Pacific Expedititon, 1897-1902, 2001, Eds. I. Krupnik, W. W. Fitzhugh, Washingnton DC.

Gurvich, I. S., 1966, Ethnic History of Siberia's NorthEast, Moscow, Nauka [In Russian].

Jochelson, W., 1905, The Koryak, The Jesup North Pacific Expedition Publications, Vol. VI, Part. I-II, Memoirs of the American Museum of Natural History, New York, Leiden, E. J. Brill, New York, G. E. Stechert \& Co.

Khakhovskaya, L. N., 2016, Field Studies by Varvara Grigoryevna Kuznetsova in the Amguema Tundra, Etnograficheskoe Obozrenie, 3, 83-95 [In Russian].

Khakhovskaya, L. N., 2017, Ethnographic Problems in the Research Program of N. N. Dikov, Journal of Historical, Philological and Cultural Studies, 1, 304-318 [In Russian].

Kolomiets, O. P., 2018, From the History of the Development of Ethnography in Chukotka, Etnografia, 2, 188 196 [In Russian].
Krasheninnikov, S. P., 1949, Description of the Land of Kamchatka, Moscow - Leningrad, Glavsevmorput' [In Russian].

Kuznetsova, V. G., 1957, Materials on Holidays and Ceremonies of the Amguema Reindeer Chukchi, Sibirskiy Etnograficheskiy Sbornik, Ethnographic Collection, 2 (Trudy Instituta Etnographiyi, New Series, Vol. 35), 263-326, Moscow - Leningrad [In Russian].

Lebedev, V. V.; Simchenko, Iu. B., 1983, Achayvayam Spring, Moscow, Mysl' [In Russian].

Leontyev, V. V., 1973, Economy and Culture of the Peoples of Chukotka (1958-1970), Novosibirsk, Nauka [In Russian].

Leontyev, V. V., 1983, Ethnography and Folklore of Kerek, Moscow, Nauka [In Russian].

Lindenau, Ya. I., 1983, Description of the Peoples of Siberia (First Half of the $18^{\text {th }}$ Century), Magadan [In Russian].

Obruchev, S. V., 1974, In the Mountains and Tundras of Chukotka, Magadan [In Russian].

Popova, U. G., 1976, Rassokha Group of Evens, Economic and Historical Research in the North-East of the USSR, Magadan, 121-140 [In Russian].

Popova, U. G., 1981, Evens of Magadan Oblast: Essays on the History, Economy, and Culture of Evens of the Okhotsk Coast 1917-1977, Moscow, Nauka [In Russian].

Rytkheu, Yu., 1991, Patient Hospitality, Sovyetskaya Chukotka, 04.16.1991 [In Russian].

Sirina A. A., 2012, Evenks and Evens in the Modern World: Self-Awareness, Nature Management, Worldview, Moscow, Vostochnaya Literatura [In Russian].

Sokolovsky, S. V., 2008, Institutes and Practices of Production and Reproduction of Ethnicity, Demoscope Weekly, 319-320 [Electronic Resource], URL: http:// www.demoscope.ru/weekly/2008/0319/analit02.php [In Russian].

Steller, G. V., 1999, Description of the Land of Kamchatka, Petropavlovsk-Kamchatsky, Kamchatka Printing House [In Russian].

Tein, T. S., 1975, Eskimo Whale Festival "Pola" (Exemplified by the Village of Naukan), Krayevedcheskiye Zapiski, Magadan, 10, 88-94 [In Russian].

Tein, T. S., 1992, And It Was So. Essays on the Traditional Culture of Asian Eskimos, Magadan, Magadan Oblast Center for Folk Art and Leisure [In Russian].

Vakhtin, N. B., 2005, Jesup Pacific Expedition and Its Russian Members, Forum for Anthropology and Culture, 2, 241-274 [In Russian]. 